\section{Casablanca no século XX: um porto, uma cidade, uma dominação}

\section{Cezar Honorato [*]}

[*] Instituto de História, Universidade Federal Fluminense (UFF). Niterói (RJ), Brasil. cezarhonorato@gmail.com

ORCID: https://orcid.org/0000-0003-4212-7395

SUÁREZ BOSA, Miguel.

Le port de Casablanca au XXe siècle.

Paris: Editions Harmattan, 2019. 231 p.
Resumo: O livro em questão busca recuperar todo o processo de construção do porto e, consequentemente, da cidade de Casablanca, Marrocos, especialmente sob o Protetorado Francês (1912-1956). Para tanto, utiliza todo o referencial da história global e suas múltiplas determinações, incluindo àquelas atinentes ao colonialismo francês na África e os impactos políticos, econômicos, sociais e empresariais.

Palavras-chave: África; Portos; Colonialismo.

Casablanca in the 20th century: a port, a city, a domination

Abstract: The book in question seeks to recover the entire process of construction of the port and, consequently, of the city of Casablanca, Morocco, especially under the French Protectorate (1912-1956). To do so, it uses the entire framework of global history and its multiple determinations, including those pertaining to French colonialism in Africa and the political, economic, social and business impacts.

Keywords: Africa, Ports; Colonialism. 
$\mathrm{N}$ o final do ano de 2019 foi publicado na França o livro do Prof. Miguel Suárez Bosa referente à história do porto de Casablanca ao longo do século XX. Trata-se de uma importante contribuição aos estudos de portos e cidades portuárias. Isto porque, além de nos apresentar um excelente exercício de história global, busca trazer à luz as marcas fundamentais da dominação europeia na região do norte da África na confluência do oceano Atlântico e do mar Mediterrâneo.

Ao longo dos anos, o Departamento de História da Universidade de Las Palmas de Gran Canarias vem se firmando como o principal centro de pesquisa das relações entre o arquipélago espanhol e a África Ocidental. Os grupos de pesquisa liderados pelos irmãos Santana Pérez (Santana Pérez; Santana Pérez, 2014) relacionados ao período moderno, por Daniel Castillo Hidalgo (Castillo Hidalgo, 2015) e pelo Prof. Catedrático Miguel Suarez Bosa, ${ }^{1}$ enfocando os séculos XIX e XX, têm se transformado em referências internacionais quando se busca entender as atividades econômicas, os portos e as cidades portuárias.

No caso do livro em apreço, o enfoque principal é o de analisar o processo de construção e desenvolvimento do porto de Casablanca durante o período do Protetorado francês do Marrocos (1912-1956) num contexto de expansão imperialista e colonialista que marca a passagem do século XIX para o século XX. Neste caso, o expansionismo francês e espanhol na África no início do século XX.

Exatamente este é um primeiro aspecto a ser considerado: a disputa entre as nações imperialistas sobre o continente africano - franceses, ingleses, belgas, espanhóis e alemães, principalmente - e o fato dessa expansão estar não só ancorada no domínio político e/ou territorial, mas na montagem de uma infraestrutura econômica de articulação desses territórios dominados pelos interesses empresariais expansionistas. Nesse sentido, o livro já se justificaria por apresentar uma análise de um processo concreto de dominação colonialista de uma fundamental região africana.

Um aspecto importante é que o autor nos apresenta um excelente quadro das transformações históricas do Marrocos desde a segunda metade do século XIX até a assinatura do Tratado de Fez (1912) — dando continuidade aos Acordos de Algeciras (1906) - que definiu a parte do chamado Marrocos Atlântico (o território mais fértil) para tutela francesa, cabendo à Espanha a porção mediterrânea, mais pobre e tradicional.

Nos primeiro e segundo capítulos, o autor nos faz um impressionante balanço historiográfico acerca da história dos portos e das cidades portuárias atlânticas, além do desenvol-

1 Dentre outras atividades, o Prof. Miguel Suarez Bosa coordena o projeto de pesquisa "Global South. Puertos y Desarrollo Económico y Social en el Atlántico Meridional (1850-2010)" e a Acción de Red Excelencia “La gobernanza de los puertos atlánticos. Siglos XV-XXl”, além de uma produção bibliográfica internacionalmente reconhecida. 
vimento dos portos da África Ocidental. A construção de portos modernos, capitalistas, na expansão do imperialismo tornou-se básica por permitir, por um lado, a integração de várias regiões do globo e, por outro, o desenvolvimento de estruturas de transportes - ferrovias por exemplo - e comunicações que viabilizassem a exportação de commodities a baixo custo para os centros capitalistas e permitissem a chegada de produtos industrializados nas regiões mais longínquas com mais segurança, rapidez e menor custo.

A partir de então, o autor se dedica mais especificamente à análise do caso do Marrocos, demonstrando que o Protetorado francês aprofundou o caráter dual de sua economia. Analisando a formação econômico-social do Marrocos, o livro chama a atenção para a existência de uma economia tradicional e pobre que vai persistir com - e ampliar? -o projeto de desenvolvimento implantado pelos franceses de montagem de uma infraestrutura moderna de transportes, especialmente as ferrovias, e do porto de Casablanca.

Evidentemente, o desenvolvimento da infraestrutura de transportes com novas ferrovias e portos, principalmente o de Casablanca, num certo sentido, permitiu o desenvolvimento de uma agricultura modernizada, especialmente cereais, e um extrativismo para a exploração e exportação de fosfato, produto líder da pauta de exportação.

Ressalve-se que essas ferrovias tinham um objetivo único: facilitar a exportação de matérias-primas para o porto e, daí, para a França e levar para o interior os produtos industrializados provenientes da Europa para aqueles poucos que enriqueciam com esta modernização. Ao final do Protetorado, como bem aponta Suarez Bosa, o Marrocos estava marcadamente caracterizado pelo subdesenvolvimento. Aliás, nada diferente do que ocorria em outras regiões da África e mesmo da América Latina e Ásia.

Uma estrutura de poder na qual o sultão compunha um Conselho de Governo do qual fazia parte - aliás, no qual dominava — o comissário residente-geral, nomeado pela França, deu aos europeus o domínio de fato do país em que atuava. Mais ainda, funcionava como agente do grande capital francês, inclusive do Banco Paribas.

O livro nos apresenta o grande debate acerca de investimentos em vários pequenos portos em comparação com a construção de um grande porto (Casablanca), que marcou os primeiros tempos do domínio forâneo. Como a estratégia era de uma maior articulação da economia marroquina com o capitalismo central, a decisão acabou sendo a da construção de um grande porto em paralelo à criação de ferrovias do interior do país para o porto.

A análise realizada pelo autor sobre o impacto da construção do porto de Casablanca sobre o crescimento urbano da cidade é impressionante. A cidade, como bem aponta, tornou-se o grande polo industrial e urbano do Marrocos sob o domínio do Protetorado e, até hoje, é um dos mais importantes portos da África Ocidental, especialmente na articulação entre o oceano Atlântico e o Mediterrâneo.

Continuando na sua pesquisa, Suarez Bosa analisa todo o processo de construção do 
porto de Casablanca, desde suas características técnicas e tecnológicas, até as inversões de capitais realizadas para a sua implementação, com destaque para os interesses dos vários grupos empresariais de origem francesa.

Merece um destaque especial a própria gestão, realizada pela Administration des Travaux Publics, com um diretor-geral que administrava as obras, os recursos e as grandes definições da operação portuária, assessorada pelo Comitê de Coordenação, presidido pelo próprio inspecteur général de Ponts et Chaussées e composto também pelos representantes do Ministério de Trabalhos Públicos, da Câmara de Comércio, da Aduana, da Polícia, da Compagnie Manutention Marocaine, Compagnie Chemins de Fer e dos agentes marítimos.

Analisando o porto de Casablanca como um barômetro da economia marroquina, o autor analisa a função comercial e os próprios intercâmbios com suas conexões internacionais, especialmente as rotas e empresas que com ele operavam. Pela profusão de dados apresentados no livro é possível percebermos, não só as formas de atuação do colonialismo francês, mas, principalmente do próprio imperialismo, dando concretude àquilo analisado pelo contemporâneo Lenin.

Mais ainda, ao recuperar os dados da movimentação do porto de Casablanca o Prof. Miguel nos apresenta um quadro importante do seu impacto sobre o hinterland e sobre a exploração de fosfato e cereais, inclusive em termos de uma logística que privilegia a produção "para fora”, em detrimento do desenvolvimento regional.

Continuando, Suarez Bosa dá destaque à administração portuária, às empresas e aos trabalhadores. Neste particular, primeiramente analisa as várias empresas diretamente envolvidas na atividade portuária como, por exemplo, as empresas de transportes e as seguradoras.

Em seguida, o foco se desloca para a análise das grandes empresas que utilizavam o porto e suas agregações corporativas de interesse, como é o caso do Office Chérifien de Phosphates (OCP), da Chambre de Commerce et d'Industrie, a gestão dos silos e a Manutention Marocaine (MM) e a presença do grande capital que operava no porto de Casablanaca através de suas filiais como a Compagnie Delmas-Vieljeux-Maroc, Paquet-Maroc, Compagnie Marocaine de Transit et d'Affrètements, Compagnie Générale Transatlantique, Messageries Maritimes, Compagnie Chérifienne d'Armement, filial de la S.A.G.A (grupo Rothschild), além das empresas de reparo naval como a Damestoy, Genestal-Afrique, Ateliers de Chantiers du Maroc y Chantiers Galinari, Compagnie Franco-Chérifienne de Navigation e Société Marocaine Charbonnière et Maritime.

Buscando olhar a questão do trabalho, a obra analisa o proletariado industrial e portuário em Casablanca considerando as suas características antes e depois do Protetorado e da construção do porto com relação à atuação da Manutention Marocaine - que passou a monopolizar toda a operação portuária sob o Protetorado - com características similares 
ao que ocorria em outros portos do mundo, como o de Santos e do Rio de Janeiro, nos quais observamos a combinação de trabalhadores fixos com os avulsos por tarefa, especialmente os carregadores e estivadores. ${ }^{2}$

Ao longo do tempo, como também ocorre em várias partes do mundo, os conflitos nas relações de trabalho vão surgindo, especialmente com a atuação da Confederação Geral do Trabalho exigindo melhorias salariais, especialmente na década de 1940, quando o próprio Protetorado começava a apresentar os primeiros sinais de esgotamento, que ocorreria na década seguinte. Embasando parte desses movimentos, temos a análise das condições de vida dos trabalhadores portuários.

Como historiador de escol e um dos maiores especialistas europeus em história dos portos e das cidades portuárias, o Prof. Miguel Suarez Bosa dedica um capítulo inteiro à análise da relação entre o porto e a cidade de Casablanca, demonstrando seu profundo domínio também da análise territorial ao longo do tempo, considerando, inclusive, questões étnicas e religiosas em consonância com a dinâmica do porto e de seus negócios.

Temas como a mão de obra nativa, a imigração de trabalhadores e a localização dessa população na cidade, além das articulações e embates entre as minorias fassi e soussi, nos dão uma excelente visão da complexidade social que Casablanca adquiriu devido ao porto, incluindo o projeto de reordenação urbana proposto por Michel Ecochard na década de 1940 e sua consolidação como a grande cidade industrial do Marrocos após a Segunda Guerra Mundial.

Muito poderíamos ainda dizer sobre as enormes virtudes do presente livro, mas, devido ao espaço permitido a uma resenha, sou obrigado a apenas apontar suas características gerais para, finalmente, implorar aos editores brasileiros que o publiquem por ser uma obra fundamental para todos aqueles que estudam os portos, a realidade contemporânea africana e, principalmente, a dinâmica colonial e imperialista francesa desde o final do século XIX até - e principalmente - do século XX!

Finalmente, a riqueza das fontes, dos dados econômicos e da bibliografia compulsada é de extrema importância para aqueles que se dedicam à análise do mundo contemporâneo, do impacto do imperialismo e colonialismo europeu na África e ainda para os que se interessam pela história dos portos e das cidades portuárias. Tudo faz da obra Le port de Casablanca au XXe Siècle, de Miguel Suarez Bosa, um trabalho seminal.

2 Nos portos brasileiros, eram conhecidos como "bagrinhos", por não serem trabalhadores formais da empresa, não terem nenhuma garantia trabalhista e trabalharem por demanda. 


\section{Referências}

CASTILLO HIDALGO, Daniel. Puerto de Dakar, puerta de África Occidental. Santa Cruz de Tenerife: Vereda Libros, 2015.

SANTANA PÉREZ, Juan Manuel; SANTANA
PÉREZ, Gérman. La pesca en el Banco Sahariano - siglos XVII e XVIII. Madrid: La Catarata, 2014.

SUÁREZ BOSA, Miguel. Le port de Casablanca au XXe siècle. Paris: Editions Harmattan, 2019. 